\title{
R Research S Surure \\ Knowledge of Alzheimer's disease among healthcare providers and medical students in Sudan
}

Ismat Babiker ( $\sim$ Ismatbabiker94@gmail.com )

Awab Elnaeim

Mohamed Elnaeim

Awab Saad

\section{Research Article}

Keywords: awareness, dementia, doctors, Africa

Posted Date: October 8th, 2021

DOl: https://doi.org/10.21203/rs.3.rs-953158/v1

License: (c) (i) This work is licensed under a Creative Commons Attribution 4.0 International License.

Read Full License

Version of Record: A version of this preprint was published at Journal of the Neurological Sciences on October 1st, 2021. See the published version at https://doi.org/10.1016/j.jns.2021.118966. 


\section{Abstract}

Objective: The purpose of this study was to assess knowledge of Alzheimer's disease among medical students and healthcare providers in Sudan.

Methods: In this cross-sectional study conducted in Sudan from July to December 2020, we used Google forms to collect data from 212 medical students and healthcare providers using Alzheimer's Disease Knowledge Scale (ADKS). ADKS is a widely used validated instrument that measures what people know about Alzheimer's disease using a 30-item true/false questionnaire across seven critical knowledge domains: risk factors, symptoms, assessment and diagnosis, disease trajectory, life impact, treatment, and management, and caregiving.

Results: Our studied population consisted of doctors $(n=106)$, medical students $(n=23)$, Nursing staff $(n=09)$, and other hospital staff $(n=74) .76 .9 \%$ were females. When rating their knowledge from $0-10$, our participants' mean value was $5.3 \pm 2.1$. Regarding ADKS, the mean knowledge score (out of 30) is $20.6 \pm$ 2.8. Regarding ADKS domains, the best average scores were treatment and management $86.8 \%$, followed by life impact $78.3 \%$, assessment, and diagnosis $72.4 \%$, course $71.5 \%$, symptoms $62.7 \%$, caregiving $59.2 \%$, and risk factors $59 \%$. We did not detect any significant association between the average overall score, occupation, source of information, or having a relative with Alzheimer's disease.

Conclusion: Specific knowledge deficits were observed in domains focusing on risk factors, symptoms, and caregiving for Alzheimer's disease.

\section{Background}

Dementia is a chief public health dilemma for both developed and developing countries (1). It is currently estimated that more than 50 million people live with dementia worldwide, and this number is anticipated to triple by 2050 (2). Dementia is a global concern not only for the cost of economic expenditure but also for the unique quality of care that people with dementia may need. Although many recognized dementia syndromes, Alzheimer's disease (AD) is the most common cause of dementia in older adults (3).

AD is one of the most predominant and debilitating medical conditions overall. Healthcare providers' knowledge about this condition must be adequate to provide high-quality patient care to this vulnerable group. More than half of the people living with dementia in the developed countries are under-diagnosed, and the diagnosis rate in developing countries is barely 5 to $10 \%$. (4). noticeably, previous studies have shown deficits in knowledge about $A D$, which was proven to culminate in underuse of medical services (5) and poorer prognosis.

Although healthcare providers' knowledge toward Alzheimer's disease was investigated in the literature, this is the first article highlighting knowledge of $A D$ among healthcare providers and medical students from Sudan or North Africa. 


\section{Objective}

The purpose of this study was to assess knowledge of Alzheimer's disease among medical students and healthcare providers in Sudan.

\section{Methods}

\section{Study design and setting}

This cross-sectional descriptive study was conducted in Sudan from July to December 2020 using an online survey distributed in social media groups that contained more than 80 thousand Sudanese healthcare providers. We used Google Forms to collect data. Google form is a tool that allows data collection via a personalized survey. The information is collected and automatically connected to a spreadsheet from which it can be imported to analysis software programs. The post included a description of the study and the consent form and requested to complete the survey. We did not collect any personal identifying information or email addresses, and the participants were completely anonymous. This method was utilized to increase the number of study participants.

\section{Data sources and measurement}

Several instruments have been developed to assess the level of knowledge in both laypeople and healthcare professionals; of these validated tools is the Alzheimer's disease Knowledge Scale (ADKS), which we used in this study.

ADKS is an updated version of the Alzheimer's disease Knowledge test (6) and consists of 30 true/false items, and the score is the number of correct answers. The scale comprises seven domains: risk factors, assessment and diagnosis, symptoms, disease course, life impact, caregiving, and treatment and management. This tool was selected in this study due to its ease of use, established reliability, and validity, in addition to its suitability to be used for various groups of healthcare experts (7).

The scale is validated in the English language. Because we conducted the study in Arabic speaking community, we sent the questionnaire to a translator to convert the ADKS to the Arabic language; after that, we conducted a pilot survey of the translated version of the questionnaire to a small group of doctors and reviewed their feedback and edited the questionnaire. The translator again examined the revised version of the questionnaire before beginning the study.

\section{Participants}

Our targeted population was medical students and healthcare providers residing in Sudan, 18 years of age or more.

\section{Statistical Methods:}

The data were analyzed using IBM SPSS statistics version 23. 
Pearson's Chi-square test to test for possible associations between variables, ANOVA test was used to compare mean scores of different study groups.

\section{Variables:}

The questionnaire consists of 3 sections. The first is informed consent. The second is the demographic data of the participants as follows:

Age groups: (18-25) (26-30) (31-40) (41 and more)

\section{Gender.}

Profession (Medical student, Doctor, Nursing, other hospital staff).

Sources of information regarding AD. (Multiple choice questions that include: university, scientific basis, social media others, and none).

Self-rated knowledge scale (from 0-10).

Do you have a family history of AD?

Have you previously been a caregiver for someone with AD?

The third section consists of the 30 items of ADKS YES or NO questions.

\section{Results}

Our studied population consisted of 212 participants, of whom 163 (76.9\%) were females. The mean age was 29 years $(S D=6.5)$, and the mean knowledge score (out of 30 ) was $20.6 \pm 2.8$. We divided the participants into four groups: Medical students $(n=23)$, Doctors $(n=106)$, Nursing staff $(n=09)$, and other hospital staff $(n=74)$.

Our participants self-rated their knowledge about Alzheimer's disease from 0-10. The mean value chosen was $5.3 \pm 2.1$. Regarding ADKS domains; The "treatment and management" domain received the highest mean percentage of correct responses (86.9\%), followed by "life impact" (78.7\%). The domains "assessment and diagnosis" (72.2\%) and "course of disease" (71.1\%) received similar mini-scores, and the three remaining domains received a relatively lower mean percentage of correct responses. These domains were "symptoms" (62.9\%), "risk factors" (59.4\%) and "caregiving" (59.2\%).

We did not detect any significant association between the average overall knowledge score and age groups, gender, or sources of information of AD. have cared for someone with AD. However, people who have a family history of AD scored better in ADKS compared to those with no family history of Alzheimer's $(p=.008)$. 
There was a positive correlation between the self-rated knowledge scale (0-10) and the overall knowledge score $\mathrm{R}=1.81, \mathrm{p}=008$.

\begin{tabular}{|c|c|c|c|c|}
\hline \multirow{2}{*}{$\begin{array}{l}\text { Background } \\
\text { characteristics }\end{array}$} & \multirow{2}{*}{$\begin{array}{l}\text { Unweighted number } \\
\text { (Weighted \%) }\end{array}$} & ADKS & \multirow[t]{2}{*}{$\mathbf{F}$} & \multirow[t]{2}{*}{ Significance } \\
\hline & & Mean (SD) & & \\
\hline \multicolumn{5}{|c|}{ Gender $(n=212)$} \\
\hline Male & $49(23.1)$ & $20.55(3.15)$ & 0.042 & .839 \\
\hline Female & 163 (76.9) & $20.64(2.69)$ & & \\
\hline Age & 73 (34.4) & $\begin{array}{l}20.27 \\
(2.95)\end{array}$ & & \\
\hline \multicolumn{5}{|l|}{$18-25$ years } \\
\hline \multirow[t]{2}{*}{$26-30$ years } & $76(35.8)$ & 20.61 & .897 & .443 \\
\hline & & $(2.47)$ & & \\
\hline \multirow[t]{2}{*}{$31-40$ years } & $54(25.5)$ & 21 & & \\
\hline & & (3.03) & & \\
\hline $41+$ years & $09(4.2)$ & $21.33(2.64)$ & & \\
\hline
\end{tabular}

Table 1: Demographic data and their relation with knowledge scores

\begin{tabular}{|l|l|l|l|l|}
\hline Professional Groups & $\begin{array}{l}\text { Number } \\
\text { (percentage) }\end{array}$ & $\begin{array}{l}\text { ADKS score } \\
\text { (Standard Deviation) }\end{array}$ & F & Significance \\
\hline Doctor & $106(50)$ & $\begin{array}{l}21.35 \\
(2.82)\end{array}$ & & \\
\hline Medical & $23(10.8)$ & $\begin{array}{l}20 \\
(2.61)\end{array}$ & 5.208 & .002 \\
\hline Nursing & $09(4.2)$ & $\begin{array}{l}20.44 \\
2.4\end{array}$ & & \\
\hline Other hospital staff & $74(34.9)$ & $\begin{array}{l}19.8 \\
(2.64)\end{array}$ & & \\
\hline
\end{tabular}

Table 2: Professional groups and their correlation with knowledge scores

\section{Discussion}

For comparison purposes, participants' occupation is divided and analyzed into four categories: Medical students, Doctors, Nursing staff, other hospital staff. 
The results from this sample of healthcare providers and medical students show a moderate level of knowledge toward Alzheimer's disease (mean knowledge score is $20.6 \pm 2.8$ out of 30 , and overall correct responses are $70 \%$ ). this is similar to what was reported in the literature. (8). As expected, participants involved directly in managing Alzheimer's disease (doctors, medical students, and nursing staff) scored better than other hospital staff, especially in the treatment and management domain $(p=.049)$. This is consistent with what was reported from Australia (8).

Although the social media groups in which the study was conducted contain a diverse and significant section of the healthcare providers in Sudan, this article is susceptible to volunteer bias, as knowledge of participants who choose to participate in the study may be different than other healthcare providers as the respondents were a self-selected group. In addition, due to the data collection method, the response rate could not be calculated.

\section{Conclusion}

Specific knowledge deficits were observed in domains focusing on risk factors, symptoms, and caregiving for Alzheimer's disease.

\section{Declarations}

\section{Ethical considerations}

The participants provided their written informed consent to participate in the study, and the consent form was attached before the data collection sheet. There are no potentially identifiable human images, or data is presented in the study.

\section{Acknowledgments}

We thank Ms. Bahja Basheer for translating the questionnaire into Arabic language.

We appreciate participants in the pilot survey for their feedback on the translated version of the questionnaire.

\section{Conflict of interest}

All authors declare that there is no conflict of interest to be disclosed.

\section{Source of funding:}

None.

\section{References}


1. Fratiglioni, L., De Ronchi, D. \& Agüero-Torres, H. Worldwide Prevalence and Incidence of Dementia. Drugs Aging 15, 365-375 (1999).

2. WHO and Alzheimer's Disease International, Dementia: A Public Health Priority

3. Henderson AS, Jorm AF. Definition, and Epidemiology of Dementia: A Review. Dementia. 2002 Feb 11;1-68. 1.

4. Comas-Herrera A, Guerchet M, Karagiannidou M, Knapp M, Prince M. World Alzheimer Report 2016: Improving healthcare for people living with dementia: Coverage, quality and costs now and in the future. 2016.

5. Bailey KE. Student awareness of Alzheimer's disease. American Journal of Alzheimer's Disease \& Other Dementias ${ }^{\circledR}$. November 2000:375-378. doi:10.1177/153331750001500610

6. Dieckmann L, Zarit SH, Zarit JM, Gatz M. The Alzheimer's disease knowledge test. Gerontologist. 1988 Jun;28(3):402-7. DOI: 10.1093/geront/28.3.402.

7. Carpenter B, Balsis S, Otilingam P, Hanson P, Gatz M. The Alzheimer's Disease Knowledge Scale: Development and psychometric properties. Gerontologist. 2009;49(2):236-247.

8. Smyth, W., Fielding, E., Beattie, E. et al. A survey-based study of knowledge of Alzheimer's disease among health care staff. BMC Geriatr 13, 2 (2013). 